\title{
INTERAÇÕES CULTURALISTAS E BIOPOLÍTICAS EM TEMPO DE PANDEMIA: ESTRATÉGIAS DE ATUAÇÃO E INTERESSES DOS USUÁRIOS DO YOUTUBE NO PERÍODO DE MARÇO A JUNHO DE 2020
}

\author{
ARTIGO ORIGINAL \\ DENDASCK, Carla Viana ${ }^{1}$ \\ OLIVEIRA, Euzébio de ${ }^{2}$
}

DENDASCK, Carla Viana. OLIVEIRA, Euzébio de. Interações culturalistas e biopolíticas em tempo de pandemia: Estratégias de atuação e interesses dos usuários do Youtube no período de março a junho de 2020. Revista Científica Multidisciplinar Núcleo do Conhecimento. Ano 05, Ed. 08, Vol. 16, pp. 38-47. Agosto de 2020. ISSN: 2448-0959, Link de acesso: https://www.nucleodoconhecimento.com.br/comunicacao/interacoes$\underline{\text { culturalistas }}$

\section{RESUMO}

Este artigo, realizado como parte do cumprimento de disciplinas do Programa de Doutorado em Comunicação e Semiótica realizado na Pontifícia Universidade Católica de São Paulo, tem como objetivo fazer uma reflexão sobre as interações culturalistas e biopolíticas adotadas em meio a epidemia do Covid-19 no Brasil entre os meses de março a junho de 2020. Para isso, utilizou-se da análise dos 50 canais mais acessados no Youtube nos últimos 4 meses, investigando se e como os usuários manifestam seus comportamentos e interesses através de suas respectivas buscas nessas

\footnotetext{
${ }^{1}$ Teóloga, Doutora em Psicanálise, pesquisadora do Centro de Pesquisa e Estudos Avançados (CEPA).

2 Biólogo, Doutor em Doenças Topicais, Professor e pesquisador do Curso de Educação Física, Universidade Federal do Pará (UFPA).
} 
mídias. Através desses resultados, realizou-se uma breve análise sobre as efetividades das políticas implementadas e seus possíveis desdobramentos.

Palavras-chave: Pandemia, interações culturalistas e biopolíticas, Youtube.

\section{INTRODUÇÃO}

Desde que os meios técnicos de comunicação passaram a expressar as manifestações de culturas, interesses e tendências coletivas, certamente, a sociedade não havia se deparado mediante uma crise causada pela anunciação do estado de Pandemia, realizado pela Organização Mundial da Saúde em março de 2020, resultante do novo COVID-19, com recomendação de isolamento social, o que remodelou as rotinas das cidades, levando centenas de milhares de pessoas utilizar seus aparatos tecnológicos (smartphones, notebook, computadores) como meio de comunicação prioritário, seja na rotina de trabalho, estudos, socialização, dentre outros.

Apesar deste estado apontado como caótico, não se pode negar que este contexto criou um ambiente para profundas reflexões, bem como, abriu portas para um campo fértil de estudos em todas as áreas, especialmente no campo da comunicação. Compreende-se até mesmo a existência de uma extensão dos lugares e espaços, aqueles que inicialmente eram delimitados e discutidos como lugares fixos e espaços abertos, públicos e privados, tomam dimensões complexas. Embora concordemos com Belting (2009, p.81) de que os espaços possuem as características de estarem organizados de maneira heterogênea e descontínua, no espaço cibernético criado pelo cenário pandêmico, que antes já transcendia essas dimensões, passam então a trabalhar numa esfera de deslocamento e compreensão própria de tempo e espaço, já que seus limites rompem barreiras físicas e passam a manifestar-se dentro de uma ambiguidade, as vezes contraditória, as vezes contributivas aos novos modos de viver, pensar, organizar, trabalhar, comemorar, sentir, relacionar, dentre outros.

Durante as aulas do doutoramento em Comunicação de Semiótica na Pontifícia Universidade Católica de São Paulo, neste primeiro semestre de 2020, o campo de 
reflexão e estudos não se distanciou desse contexto apresentado. Primeiro pela necessidade de uma rápida adaptação de rotinas, especialmente nas mudanças de ambientes presenciais para o ambiente online, tanto por parte dos alunos que vivenciaram adaptações de novas rotinas de estudos, quanto dos professores que precisaram aprender um novo sistema de comunicação, sistema esse que obedece a certos processos e linguagens próprias. Há ainda o cenário da ministração da aula em $\mathrm{si}$, onde tanto professores quanto alunos tiveram que se adaptar a novos formatos de interações durante as aulas. Esse contexto certamente ocasionou a sensação de estranhamento inicial.

Posteriormente, não se pode deixar mencionar que todos os textos, embora tenham sido escolhidos anteriormente a esse estado pandêmico, serviram como aporte para aprofundar reflexões contemporâneas, quase como se tivessem sido previstos. Talvez por que as áreas de estudos e temas abordados pela comunicação tenham esse poder atemporal, ou, talvez, pela maestria dos professores em se apropriarem dos temas e trazerem as reflexões aos dias atuais. Mais do que nunca se compreendeu que sem os meios técnicos não é possível falar em comunicação como ciência, assim, evidenciou-se que a tecnologia é fundamental para a sobrevivência da comunicação como área do saber.

Essas contribuições fizeram com que as coletas mensais dos 50 canais mais acessados no Youtube que estão sendo realizadas como parte das investigações da tese final, bem como, as análises de suas estratégias comunicacionais fossem sendo ressignificadas na medida em que as aulas e os textos trabalhados foram demonstrando novos modos de manifestações e possibilidades de compreensão dos interesses dos usuários.

Lembremos que o interesse pela plataforma do Youtube se dá especialmente pelo fato de que, nesta plataforma, o usuário "escolhe" o que quer assistir, ao contrário de outros meios de comunicação, como o televisivo que executa uma programação baseada em outras estratégias. Na plataforma do youtube, a velocidade da comunicação, a democratização dos produtores de conteúdos em diferentes formatos, a pluralidade de públicos, as formas de interações e as ações para se sobressair na 
medida "em que se é escolhido" faz com que esta plataforma seja capaz de exprimir os interesses de uma parcela significativa da sociedade contemporânea, seja por nicho, seja no coletivo.

Assim, organizou-se esse material em dois momentos: O primeiro fazendo uma breve alusão sobre a pandemia, como foram sendo implementadas as políticas e a criação de uma comunicação do pânico e do medo pelos principais meios de comunicação no Brasil. No segundo momento, demonstramos como isso refletiu nas buscas pelas redes sociais, especialmente no youtube. Por fim, as conclusivas fazem algumas reflexões sobre alguns aspectos que envolvem os interesses e estratégias que estão sendo absorvidos pelos usuários dessa rede.

\section{BREVES CONSIDERAÇÕES ACERCA DA PANDEMIA / COMUNICAÇÃO E BIOPOLÍTICAS DE CONTROLE}

O Coronavirus é uma espécie de vírus mutante já conhecida pelos estudiosos desde a década de 70. No entanto, a variação conhecida como COVID-19 ou SARS-CoV-2, foi descoberta no segundo semestre de 2019, em Wuhan na China. O que levou a Organização Mundial da Saúde considerar esse vírus como pandêmico é seu alto poder de propagação e a capacidade de evolução para pneumonia aguda, considerada de alto risco de morbimortalidade para alguns grupos de indivíduos (SILVA et. al. 2020).

O desconhecimento sobre sua origem, suas variáveis de evolução, e desdobramentos colocou as autoridades do mundo inteiro a adotar um discurso homogêneo e tomar medidas restritivas severas, levando a população a uma situação de pânico. Rapidamente a sociedade, desde os líderes até os pequenos grupos, evidenciou a incapacidade emocional de lidar com o medo, com a impotência mediante a vida, tomando medidas que Agamben (2020) chamou de frenéticas e irracionais, sem estudos multidisciplinares quanto suas consequências, adotando um discurso "pela vida" que acabou por desembocar em centenas de outros problemas socioeconômicos, bem como de saúde coletiva, como depressão, ansiedade, suicídio, obesidade dentre outros. 
De acordo com Agamben (2009, p.50), "quanto mais os dispositivos se difundem e disseminam o seu poder em cada âmbito da vida, tanto mais o governo se encontra diante de um elemento inapreensível [...]". No processo pandêmico, os sujeitos ficaram a mercê das biopolíticas governamentais, dispositivos de controle foram implementados, e logo viu-se instalar diversas formas de outras crises, como crise econômica, crise entre poderes.

$\mathrm{Na}$ sociedade contemporânea, tais dispositivos apesar de atuarem de forma impactante e direta, também são capazes de tomar desdobramentos além das compreensões de tendências, que acabam sendo responsáveis pelas novas formas de biopolíticas. Sobre o COVID-19, Agamben (2020) apontou que o medo, o temor de se contagiar e contagiar os outros levaram as biopolíticas de restrição de liberdade a serem aprovadas, mesmo que sem muitas discussões sobre suas consequências, por grande parte da população mundial. Autoridades mundiais e as mídias se muniram para espalhar a sensação de pânico, afirmando a tendência crescente do estado de exceção que, neste caso, permitiu uma espécie de "militarização" de fazer o que se bem entender com toda uma sociedade por parte daqueles que tem o poder.

Por um instante esqueceu-se da "multiplicidade de dramas sociais" para olhar apenas um problema, apenas um foco, e em nome dele, aceitar uma ditadura velada, e de certa forma, apoiada por diversos públicos, usando técnicas biopolíticas.

Segundo Lazzarato (2006, p.81): "As técnicas que biopolíticas são endereçadas a vida, dirigem-se ao ser vivente enquanto pertencente a espécie humana. Visam regular a vida atingida pela doença, pelo desemprego, pela velhice, pela morte".

O grande problema é que essa atuação de controle desembocou numa crise social do pensar, polarizaram-se posicionamentos que reduziram o real problema pandêmico aos posicionamentos e condições pessoais, impedindo as pessoas de agir ou pensar em coletivo, porém, usando termos como "em nome da vida" grupos dividiram-se, e os líderes estadistas usaram esses cenários para fazer políticas e biopolíticas de controle que atuaram sobre o princípio e direito da liberdade, usando grupos de interesses diversos, além de apropriarem-se dessas condições para que políticas 
públicas emergenciais permitissem a ausência de licitações, impulsionando um cenário para outra crise, "a corrupção".

Entre os meses de março a maio, a televisão aberta criou um clima de pânico, suspendeu a programação normal para enfatizar exaustivamente sobre a pandemia. O que deveria ser informação, virou também cenário político e criou uma espécie de vácuo entre as ações e condutas necessárias e as realizadas, enfatizando a moldagens dos corpos, porém, agora, de forma ambígua. A sociedade de controle experimentou seu descontrole, ou seja, as informações e avanços tecnológicos continuam, mas o que fazer com essas informações para produzir biopolíticas afirmativas em período de crise se há uma crise existencial do medo? Essa resposta ainda parece não ter sido incorporada nem pela sociedade, tão pouco pelos seus líderes. No entanto, algumas pistas sobre esses desdobramentos podem ser encontradas através das manifestações de interesses de acordo com as buscas nas redes sociais, como iremos demonstrar na sequência desse estudo.

\section{O YOUTUBE COMO FORMA DE MANIFESTAÇÃO DOS INTERESSES}

Como já aludido anteriormente, para reunir os dados da tese de doutoramento, são investigados os 50 canais mais acessados do Youtube e as estratégias utilizadas por esses canais na criação de conteúdo para alcançar seus respectivos usuários. Após o mês de março de 2020, período que se iniciou a quarentena, observou-se a criação de tendências que antes não existiam, como a prevalência das lives de cantores, o interesse relacionado ao COVID-19, nos primeiros dois meses, e o forte desinteresse após o mês de maio. Em contrapartida, também se evidenciou a utilização desta plataforma no setor de educação por parte de alguns estados, levando o aumento de acesso por parte do público infantil e juvenil. Neste período, o Youtube reviu suas políticas internas e decidiu não mais monetizar os canais direcionados a esses públicos, havendo então uma queda de produção de conteúdo direcionada a essa faixa etária. Abaixo encontra-se a tabela dos 50 vídeos dos canais mais acessados do Youtube. 
Tabela 1- 50 videos mais acessados

\begin{tabular}{|c|c|c|c|c|c|c|c|c|}
\hline Categoria & Mar & & Abr & & Mai & & Jun & \\
\hline & $\begin{array}{l}\text { Quan } \\
t\end{array}$ & $\%$ & $\begin{array}{l}\text { Quan } \\
t\end{array}$ & $\%$ & $\begin{array}{l}\text { Quant } \\
\text { i }\end{array}$ & $\%$ & $\begin{array}{l}\text { Quan } \\
\mathrm{t}\end{array}$ & $\%$ \\
\hline Covid & 6 & $12 \%$ & 4 & $8 \%$ & 2 & $4 \%$ & 0 & $0 \%$ \\
\hline Live & 0 & 0 & 1 & $2 \%$ & 15 & $30 \%$ & 22 & $\begin{array}{l}44 \\
\%\end{array}$ \\
\hline Música & 6 & $12 \%$ & 8 & $16 \%$ & 4 & $8 \%$ & 0 & $0 \%$ \\
\hline BBB & 3 & $6 \%$ & 3 & $6 \%$ & 0 & $0 \%$ & 0 & $0 \%$ \\
\hline $\begin{array}{l}\text { Comentário de } \\
\text { Filmes }\end{array}$ & 3 & $6 \%$ & 2 & $4 \%$ & 0 & $0 \%$ & 0 & $0 \%$ \\
\hline $\begin{array}{l}\text { Vlogueiros - } \\
\text { Demonstração de } \\
\text { Rotinas }\end{array}$ & 6 & $12 \%$ & 3 & $6 \%$ & 3 & $6 \%$ & 5 & $\begin{array}{l}10 \\
\%\end{array}$ \\
\hline $\begin{array}{l}\text { Cultura Ásia } \\
\text { Oriental }\end{array}$ & 1 & $2 \%$ & 1 & $2 \%$ & 1 & $2 \%$ & 4 & $8 \%$ \\
\hline Exercícios Físicos & 3 & $6 \%$ & 1 & $2 \%$ & 2 & $4 \%$ & 0 & $0 \%$ \\
\hline $\begin{array}{l}\text { Comentários sobre } \\
\text { beleza estética }\end{array}$ & 1 & $2 \%$ & 0 & $0 \%$ & 1 & $2 \%$ & 1 & $2 \%$ \\
\hline Alimentação & 6 & $12 \%$ & 4 & $8 \%$ & 4 & $8 \%$ & 1 & $2 \%$ \\
\hline Gospel/ Religioso & 2 & $4 \%$ & 2 & $4 \%$ & 3 & $6 \%$ & 1 & $2 \%$ \\
\hline $\begin{array}{l}\text { Canais de Atores } \\
\text { Famosos } \\
\text { televisão }\end{array}$ & 4 & $8 \%$ & 3 & $6 \%$ & 1 & $2 \%$ & 0 & $0 \%$ \\
\hline Esporte & 2 & $4 \%$ & 1 & $2 \%$ & 1 & $2 \%$ & 2 & $4 \%$ \\
\hline Carro & 1 & $2 \%$ & 1 & $2 \%$ & 0 & $0 \%$ & 1 & $2 \%$ \\
\hline $\begin{array}{l}\text { Computadores/ } \\
\text { Informática }\end{array}$ & 0 & 0 & 3 & $6 \%$ & 0 & $0 \%$ & 1 & $2 \%$ \\
\hline Jogos & 3 & $6 \%$ & 3 & $6 \%$ & 2 & $4 \%$ & 5 & $\begin{array}{l}10 \\
\%\end{array}$ \\
\hline
\end{tabular}




\begin{tabular}{|c|c|c|c|c|c|c|c|c|}
\hline Comédia/Humor & 1 & $2 \%$ & 1 & $2 \%$ & 1 & $2 \%$ & 4 & $8 \%$ \\
\hline $\begin{array}{l}\text { Ciência } \\
\text { Educação }\end{array}$ & 2 & $4 \%$ & 4 & $8 \%$ & 3 & $6 \%$ & 2 & $4 \%$ \\
\hline $\begin{array}{l}\text { Casa, decoração e } \\
\text { Jardim }\end{array}$ & 0 & 0 & 0 & $0 \%$ & 0 & $0 \%$ & 1 & $2 \%$ \\
\hline Horoscopo & 0 & $0 \%$ & 2 & $4 \%$ & 0 & $0 \%$ & 0 & $0 \%$ \\
\hline $\begin{array}{l}\text { Negócio/ } \\
\text { Empreendedorism } \\
\text { o }\end{array}$ & 0 & $0 \%$ & 3 & $6 \%$ & 3 & $6 \%$ & 0 & $0 \%$ \\
\hline Fofoca & 0 & $0 \%$ & 0 & $0 \%$ & 3 & $6 \%$ & 0 & $0 \%$ \\
\hline Total & 50 & $\begin{array}{l}100 \\
\%\end{array}$ & 50 & $\begin{array}{l}100 \\
\%\end{array}$ & 50 & $\begin{array}{l}100 \\
\%\end{array}$ & 50 & 100 \\
\hline
\end{tabular}

Fonte: Própria

Na tabela acima, é possível perceber alguns desdobramentos do contexto pandêmico através dos interesses dos usuários. No mês de março, quando se criou a política de isolamento e ainda se tinha muito desconhecimento do vírus, os canais que abordavam sobre o Covid-19 destacavam-se entre os mais acessados do canal (12\%) dos 50 canais mais acessados. Inclusive durante os dois meses iniciais (março e abril) um dos canais mais acessados trazia um contexto de terror pandêmico e previsão apocalíptica do vírus. No entanto, com o passar dos meses, o interesse dos usuários foi regredindo até que, neste mês de junho, o interesse pela temática não atingiu os 50 vídeos diários mais assistidos.

Por outro lado, a criação de lives e sua representatividade no acesso e interesse dos usuários, chegando ao percentual de $44 \%$ (entre os 50 videos) dos vídeos mais acessados, demonstram que esses usuários estão ávidos por entretenimento, especialmente aqueles eventos que trazem a imagem/memória dos eventos sociais.

Nota-se ainda que, no início da pandemia, os interesses eram mais pulverizados, havia interesse alto pela prática de exercício físico em casa, comentário de filmes e 
entretenimentos. No entanto, à medida em que os meses foram passando, esses interesses foram caindo. De igual forma, os canais dos famosos, que começaram tendo uma assiduidade de conteúdo e, que consequentemente promoveram um formato de acessibilidade relevante, com o passar dos meses parece ter diminuído seu interesse pela produção desse tipo de conteúdo.

Já no mês de abril, quando os primeiros traços de crise econômica começaram a evidenciar-se, especialmente pelo fechamento de comércios, os canais de empreendedorismo e negócio tiveram uma alta de procura que, logo depois, deixou de despertar interesse.

Há alguns tipos de canais que mantém seu nível de procura e produção de conteúdo, apresentando certa constância percentual nos meses, dentre eles: Culinária, jogos, educação, esporte e os vlogs que demonstram as vidas cotidiana de alguns youtubers.

\section{CONSIDERAÇÕES FINAIS}

O estudo da comunicação como ciência é capaz de fornecer subsídios para diversas áreas do conhecimento, bem como, para sociedade. Seus signos e representações através de suas dinâmicas traz ainda embasamento para compreensão de possíveis desdobramentos, como foi possível observar através dos dados coletados no Youtube.

Os interesses dos usuários nos meses de pandemia, demonstram que inicialmente houve um temor maior e busca por compreensão por parte desta população de usuários. No entanto apresenta, com o passar dos meses, um desinteresse coletivo, provavelmente pelas dimensões políticas e ações polarizadas que esta temática tomou no Brasil. Parece ainda, que a população não está animada com a rotina de casa. O interesse pela live, e a proporção como estas aparecem na lista de maiores destaques, apontam ainda uma população buscando por uma espécie de abstração através do entretenimento e ansiedade em socializar-se o que pode ocasionar um efeito manada dos encontros e festas antes do período desejado, agravando ainda mais os efeitos dessa pandemia. Por fim, este estudo irá continuar suas respectivas 
coletas mensalmente, proporcionando ainda mais dados para futuras análises com maior nível de profundidade.

\section{REFERÊNCIAS}

AGAMBEN, Giogio. O que é o contemporâneo? E outros ensaios. Ed. Argos, Chapecó, 2009.

AGAMBEN, Giorgio et. al. Sopa de Whuan. ASPO. 2020

BELTING, Hans. Antroplogia de la imagem. Katz Editores. Madrid, 2009.

LAZZARATO, Maurizio. As revoluções do capitalismo. Ed. Civilização brasileira . Rio de Janeiro, 2006

SILVA, Anderson Walter Costa, et al. Perfil epidemiológico e determinante social do COVID-19 em Macapá, Amapá, Amazônia, Brasil. Revista Científica Multidisciplinar Núcleo do Conhecimento. Ano 05, Ed. 04, Vol. 04, pp. 05-27. Abril de 2020. ISSN: 2448-0959, Link de acesso: https://www.nucleodoconhecimento.com.br/saude/covid19-em-macapa, DOI: 10.32749/nucleodoconhecimento.com.br/saude/covid-19-emmacapa

Enviado: Agosto, 2020.

Aprovado: Agosto, 2020. 